\title{
Association of Pre- Peri- and Postnatal Factors with Developmental Defects of Enamel in Schoolchildren
}

\author{
Fabiana Vargas-Ferreira*/ Marco Aurelio Peres**/ Samuel Carvalho Dumith***/ William Murray \\ Thomson****/ Flávio Fernando Demarco*****
}

\begin{abstract}
Objective: This study estimated the prevalence, extent, buccal distribution and associated factors involving enamel defects in Brazilian schoolchildren. Study design: A cross-sectional study using a multistage cluster random sample of 1,206 8-12-year-old Brazilian schoolchildren was carried out in Pelotas, Brazil. The prevalence of enamel defects in the permanent dentition was determined using the modified Developmental Defects of Enamel index (DDE). Sociodemographic and health data were collected from their mothers using a semi-structured questionnaire. Data were analyzed using Poisson regression modelling for DDE prevalence and negative binomial regression modelling for the extent of DDE. Results: The prevalence of any enamel defects was $64.0 \%$ (95\% Confidence Interval: 61.4, 67.0); the main types were diffuse opacities (35.0\%), demarcated opacities (29.5\%) and hypoplasia (3.7\%). In general, older children had a lower prevalence and extent of enamel defects than their counterparts $(p<0.001)$. There were no other significant associations. Conclusion: Enamel defects are common, especially among younger children, but the role of pre-, peri- and postnatal exposures remains unclear.
\end{abstract}

Key words: epidemiology, children, developmental defect of enamel, hypoplasia

\section{INTRODUCTION}

$\mathrm{E}$ namel defects are one of the most frequently observed developmental abnormalities of the human dentition'. They are disturbances arising in hard tissue matrices and in their mineralization during odontogenesis, and, because of the non-remodeled nature of teeth, enamel defects can provide a window into the "metabolic memory" of the developmental process through the relevant stage of the life course $e^{2}$. They can be classified as either opacities (qualitative defect) involving an alteration in enamel translucency or hypoplasia (quantitative defect) whereby the enamel is thinner / absent ${ }^{3}$.

*Fabiana Vargas-Ferreira, DDS, MSc, PhD, Universidade Luterana do Brasil, Canoas, Brazil

**Marco Aurelio Peres, DDS, MSc, PhD, Australian Research Center for Population Oral Health, University of Adelaide, Australia.

***Samuel Carvalho Dumith, DDS, MSc, PhD, Federal University of Rio Grande, Brazil.

****William Murray Thomson, DDS, MSc, PhD, Sir John Walsh Research Institute, University of Otago, Dunedin, New Zealand.

*****Flávio Fernando Demarco, DDS, MSc, PhD, Federal University of Pelotas, Pelotas, Brazil.

Send all correspondence to:

Fabiana Vargas-Ferreira

Universidade Luterana do Brasil (ULBRA) - School of Dentistry

Av. Farroupilha 8001 / Building 59 / Floor 3 / zip code 92425-900, Canoas,

RS, Brazil

Phone: 555134774000 / 555134771313

E-mail: fabivfer@yahoo.com.br
Each tooth develops through a well-defined sequence to achieve its morphologic and functional maturity ${ }^{4}$ and, during its formation, teeth can be subject to nutritional and non-nutritional disturbances; as a consequence, tooth status can reflect a child's development and exposures (such as undernutrition and childhood infections) during the pre-natal and post-natal periods ${ }^{5,6}$. The formation of enamel involves three phases - secretory, calcification and maturation — during which perturbations may occur, producing enamel defects ${ }^{4}$. Opacities are a result of either a sudden severe disturbance to a discrete number of cells during the maturation stage of enamel, or a less severe but longer lasting disturbance during their secretory phase. Hypoplasia results from a sudden severe insult while in the secretory phase ${ }^{5}$. Generally, demarcated opacities and enamel hypoplasia appear isolated in their distribution and have a local cause. By contrast, diffuse opacities are believed to result from systemic factors ${ }^{3,4}$.

From the few population-based studies which have investigated the occurrence of enamel defects in the permanent dentition, the reported prevalence estimates range from $21 \%$ to nearly $100 \%{ }^{7-10}$. These differences may be explained due to index used, teeth examined, conditions of buccal exam and other factors (demographic, socioeconomic and maternal-child).Developmental enamel defects may have an impact on individuals through impairing aesthetics, especially if the maxillary incisor teeth have been affected ${ }^{9-10}$. Thus, there is little evidence that these conditions are a relevant public health problem, but it can be argued that they comprise a relevant clinical condition because of their potential aesthetic impact on the maxillary incisor teeth ${ }^{10}$, which can be considerable ${ }^{9}$. 
Some studies have investigated the etiology of enamel defects and its association with maternal-child characteristics, including breastfeeding ${ }^{11-13}$ and episodes of fever and other conditions occurring during pregnancy or in the first three years of life ${ }^{14-15}$. While some studies have found an influence of some pre-, peri- and postnatal factors in the occurrence of enamel defects ${ }^{6,15}$, but the explanations are not reliable. Also, there is still debate in relation to the role of socio-economic differences in the occurrence of enamel defects. ${ }^{6,10}$ The etiology of enamel defects has not been completely elucidated, because it is difficult to identify the various factors that affect the ameloblasts from the prenatal period until the first three years of childhood.

Accordingly, this study aimed to describe the occurrence of enamel defects and their association with pre-, peri- and postnatal characteristics in a population-based sample of Brazilian schoolchildren.

\section{MATERIALS AND METHOD}

This study was a secondary analysis of cross-sectional data collected from a representative sample of 8- to 12-year-old schoolchildren from private and public schools, in Pelotas, in Brazil. A two-stage cluster sampling procedure was used. The first stage units were all primary schools in the city. The second stage units were the classrooms. Further information on the sampling strategy is available in a previous report ${ }^{16}$.

For the sample size calculation, the following parameters were used: an assumed prevalence of $29.6 \%{ }^{8}$, a sampling error of $3 \%$, and a confidence level of $95 \%$. In addition, we applied a design effect of 1.4 , based on the approach used in a similar study ${ }^{9}$, a statistical power of $80 \%$, adding $10 \%$ to compensate for refusals and $10 \%$ for controlling confounding factors. The minimum sample size to satisfy these requirements was estimated to be 772 children.

Data were collected between August and November of 2010. Detailed information about calibration and intra-oral examination procedures is available in an earlier report ${ }^{16}$. The Modified DDE index was used to classify the enamel of the permanent teeth $[46,3$ $6,24,23,22,21,11,12,13,14]^{3}$. Inter-examiner weighted kappa values for the DDE ranged from 0.71 to 0.82 .

Demographic and socioeconomic background data were collected through a questionnaire that was completed by the children's mothers at home. The questionnaire provided information related on the age, sex, type of school, mothers' years of education and quintile of monthly household income. Mothers answered questions about their health during pregnancy, and their child's health for the first three years of life. These included pregnancy disorders, malnutrition or infection during pregnancy and peri-and post-natal characteristics (malnutrition, infection, duration of exclusive breastfeeding, type of delivery, prematurity, history of dental trauma and tooth brushing with fluoridated toothpaste before age three years).

\section{Data analysis}

The analyses were carried out considering both, the literature related to the topic and a theoretical model considering the temporal sequence of events. This model incorporated different levels for health determinants: genetic or biological, social environment, behavioral health and related medical/dental care. ${ }^{17}$ In other words, that model took distal, intermediate and proximal levels of influence into account. The distal level included demographic and/or socioeconomic variables; the intermediate level included maternal health variables, and the proximal level included the child characteristics.

Water fluoridation started in 1961 in the city of Pelotas, and the levels of fluoride used are within those recommended by federal legislation (between 0.6 and $1.0 \mathrm{ppm} \mathrm{F}^{-}{ }^{18}$. All analyses took the complex sampling into account. Data analyses were performed using STATA software 12.0 (Stata Corp., College Station, TX, USA). We used the "svy" set of commands in Stata because they take into account the complex sampling design (cluster sampling in two stages: schools and classrooms). The prevalence of each type of enamel defects (demarcated and diffuse opacities and enamel hypoplasia) was determined, with a case being a child with 1 or more of a particular defect type. The other outcome (the extent of enamel defects) was assessed as a count variable. The extent of enamel defects was computed as the percentage of examined teeth with a defect, and it was determined for each defect type (please note that this differs from the tooth-level extent recorded in the DDE, where each defect's coverage of the tooth crown is recorded). Initially, descriptive analyses were performed, and then bivariate analyses with the Rao-Scott modified Chi-square. All variables with a $P$-value $<0.30$ in the bivariate analysis were considered potential confounders and were therefore included in the Poisson multivariable regression (prevalence ratio). For the outcome extent, the crude analysis was used as bivariate (data are not shown). We used negative binomial outcome analysis (of the extent, as a count ratio).

The various types of enamel defects differ in their etiology, and we identified potential determinants from the literature ${ }^{5-6,13-15}$. All maternal-child characteristics were analyzed for all three main types, but fluoridated toothpaste use before age three was included only in the assessment of diffuse opacities (this was not intended as an overall proxy measure for total fluoride exposure; rather, its inclusion reflects the fact that small children tend to swallow more toothpaste than they spit out, and so a child using it at a very young age is likely to have ingested sufficient fluoride to the point where he/she may be at greater risk of diffuse opacities of enamel in the teeth which are developing and maturing at that time). Similarly, dental trauma was included only for demarcated opacities and enamel hypoplasia. Explanatory variables were selected for the final models only if they were significantly associated with the outcomes.

The project was approved by the Human Ethics Research Committee of the Federal University of Pelotas and by the Education Department. All children's parents received a letter explaining the aims of the study, ensuring confidentiality and requesting their consent.

\section{RESULTS}

The participation rate was $69.2 \%(n=1,211)$ of all children who received letters of invitation $(n=1,744)$. Five children refused to participate during the activity day, making the final sample 1,206. Reasons for non-participation were mainly a lack of parental consent $(24.0 \%)$ or the child's absence on the day of the examination $(6.0 \%)$. The participation rate was similar between the public and private schools.

Table 1 presents data on the characteristics of the sample. $52.7 \%$ were female, and $79.6 \%$ attended in public school. 55\% were breastfed exclusively for less than six months and $42.7 \%$ of children had mothers with more than 12 years of education. 
Data on enamel defect prevalence are presented in Table 2. Almost two-thirds had one or more enamel defects, with enamel hypoplasia being the least common. The proportion of children with DDE in incisors and canines was $44.0 \%$ and $10.0 \%$, respectively. For premolars and molars, it was $23.0 \%$ and $21.0 \%$, respectively.

Data on the number of teeth showing each defect type (or combination) are shown in Figure 1. Of the 11,122 index teeth examined, $1,511(13.6 \%)$ had at least one enamel defect recorded (1,511 with the main three types). Nearly $7 \%$ of examined had diffuse opacities, and only $0.5 \%$ showed had hypoplasia.

In relation to the distribution of defect type by type of tooth among affected teeth. The most common defect among affected teeth was the diffuse opacity $40 \%$; this was followed by demarcated opacities $(26.4 \%)$, other defects $(24.4 \%)$, and combined defects (5.2\%). $3.7 \%$ of examined teeth had enamel hypoplasia. In relation to affected teeth, incisors $(52.0 \%)$ were the most commonly affected by any enamel defects, followed by premolars $(21.5 \%)$, molars $(18.0 \%)$ and canines $(8.5 \%)$.

Data on enamel defects prevalence by child and family characteristics are shown in Table 3. There were no significant associations.

The outcomes of the multivariate modelling of defect prevalence are shown in Table 4. There were no systematic differences in enamel defect prevalence by sociodemographic or maternal-child characteristics.

In Table 5, the outcomes of the models for the extent of enamel defects are presented. The extent of diffuse opacities was lowest among 12-year-olds (with the reference group being 8-year-olds), as was the extent of demarcated opacities. There were no other statistically significant associations.

Table 1-Demographic, socioeconomic and maternal child characteristics of the sample.

\begin{tabular}{lc}
\hline \multicolumn{1}{c}{ Variables } & $\mathbf{N}^{\mathrm{a}}(\%)$ \\
\hline Number N (\%) & $1206(100.0)$ \\
Sex & 1206 \\
Female & $633(52.7)$ \\
Male & $570(47.3)$ \\
Type of school & 1,203 \\
Public & $958(79.6)$ \\
Private & $245(20.4)$ \\
Age (years) & 1,203 \\
8 & $181(15.0)$ \\
9 & $311(26.0)$ \\
10 & $293(24.4)$ \\
11 & $258(21.4)$ \\
12 & $160(13.2)$ \\
Household income (quintiles) & 1,037 \\
1 (poorest) & $233(22.5)$ \\
2 & $197(19.0)$ \\
3 & $203(19.5)$ \\
4 & $223(21.5)$ \\
5 (richest) & $181(17.5)$ \\
&
\end{tabular}

\begin{tabular}{|c|c|}
\hline Variables & $N^{a}(\%)$ \\
\hline Maternal schooling (years) & 1,176 \\
\hline$\geq 12$ & $502(42.7)$ \\
\hline $9-11$ & $121(10.3)$ \\
\hline $5-8$ & $127(11.0)$ \\
\hline$\leq 4$ & $426(36.0)$ \\
\hline Maternal diabetes & 1,167 \\
\hline No & $1085(93.0)$ \\
\hline Yes & $82(7.0)$ \\
\hline Maternal infection & 1,148 \\
\hline No & $777(67.5)$ \\
\hline Yes & $368(32.5)$ \\
\hline Maternal malnutrition & 1,171 \\
\hline No & $676(57.7)$ \\
\hline Yes & $495(42.3)$ \\
\hline Infections in infancy (first three years) & 1,167 \\
\hline No & $441(37.8)$ \\
\hline Yes & $726(62.2)$ \\
\hline $\begin{array}{l}\text { Malnutrition in infancy (first three } \\
\text { years) }\end{array}$ & 1,177 \\
\hline No & $901(76.5)$ \\
\hline Yes & $276(23.5)$ \\
\hline Dental trauma (first three years) & 1,166 \\
\hline No & $912(78.2)$ \\
\hline Yes & $254(21.8)$ \\
\hline Breastfeeding (exclusively) & 1,179 \\
\hline No & $112(9.5)$ \\
\hline Yes & $1067(90.5)$ \\
\hline Breastfeeding exclusively(months) & 1,203 \\
\hline$\leq 6$ & $661(55.0)$ \\
\hline$>6$ & $542(45.0)$ \\
\hline $\begin{array}{l}\text { Brushing with fluoridated toothpaste } \\
\text { (years) }\end{array}$ & 1,164 \\
\hline$<3$ & $859(73.8)$ \\
\hline$\geq 3$ & $305(26.2)$ \\
\hline Type of delivery & 1,169 \\
\hline Vaginal & $721(62.0)$ \\
\hline Caesarean & $448(38.0)$ \\
\hline Prematurity & 1,175 \\
\hline No & $1036(88.2)$ \\
\hline Yes & $139(11.8)$ \\
\hline \multicolumn{2}{|c|}{ aValues lower than 1206 due incomplete data (main sample) } \\
\hline
\end{tabular}


Table 2 - Prevalence of enamel defects in Brazilian schoolchildren.

\begin{tabular}{|c|c|c|c|}
\hline \multicolumn{2}{|l|}{ Variables } & \multicolumn{2}{|l|}{ Variables } \\
\hline Total & $\mathbf{N}(\%)$ & Total & N (\%) \\
\hline \multirow[b]{2}{*}{ Any developmental enamel defects } & $1206(100.0)$ & $\begin{array}{l}\text { Proportion of children with } 1 \text { or more DDE in } \\
\text { incisors }^{a}\end{array}$ & 1,205 \\
\hline & 1,206 & 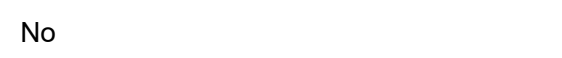 & $671(55.6)$ \\
\hline No & $435(36.0)$ & Yes & $534(44.4)$ \\
\hline Yes & $776(64.0)$ & \multirow{2}{*}{$\begin{array}{l}\text { Proportion of children with } 1 \text { or more DDE in } \\
\text { canines }^{\mathrm{a}}\end{array}$} & \multirow{2}{*}{1,154} \\
\hline Enamel hypoplasia & 1,206 & & \\
\hline No & $1162(96.3)$ & No & $1035(89.7)$ \\
\hline Yes & $44(3.7)$ & Yes & $119(10.3)$ \\
\hline Demarcated opacity & 1,206 & $\begin{array}{l}\text { Proportion of children with } 1 \text { or more DDE in } \\
\text { premolars }^{\mathrm{a}}\end{array}$ & 1,190 \\
\hline No & $850(70.5)$ & \multirow{2}{*}{ No } & $918(771)$ \\
\hline Yes & $356(29.5)$ & & $272(22.8)$ \\
\hline $\begin{array}{l}\text { Diffuse opacity } \\
\text { No }\end{array}$ & $\begin{array}{c}1,206 \\
788(65.3)\end{array}$ & $\begin{array}{l}\text { Proportion of children with } 1 \text { or more DDE in } \\
\text { molars }^{a}\end{array}$ & 1,186 \\
\hline Yes & $418(34.7)$ & No & $939(79.2)$ \\
\hline \multicolumn{2}{|c|}{$\begin{array}{l}\text { a Some schoolchildren did not have those permanent teeth erupted in the } \\
\text { oral cavity }\end{array}$} & Yes & $247(20.8)$ \\
\hline
\end{tabular}

Table 3 - Bivariate analysis between prevalence of types of enamel defects and demographic, socioeconomic and maternal child characteristics of the sample.

\begin{tabular}{|c|c|c|c|c|c|c|c|c|c|}
\hline \multirow{2}{*}{ Variables } & \multicolumn{3}{|c|}{$\begin{array}{l}\text { Prevalence of demarcated } \\
\text { opacity }^{d}\end{array}$} & \multicolumn{3}{|c|}{ Prevalence of diffuse opacity ${ }^{d}$} & \multicolumn{3}{|c|}{$\begin{array}{c}\text { Prevalence of enamel } \\
\text { hypoplasia }^{\mathrm{d}}\end{array}$} \\
\hline & $\mathbf{N}$ & $\%$ & $\mathbf{P}$ & $\mathbf{N}$ & $\%$ & $\mathbf{P}$ & $\mathbf{N}$ & $\%$ & $\mathbf{P}$ \\
\hline Sex & 356 & 29.5 & $0.554^{a}$ & 418 & 34.7 & $0.794^{a}$ & 44 & 3.7 & $0.676^{\mathrm{a}}$ \\
\hline Male & 163 & 28.6 & & 200 & 35.0 & & 22 & 3.8 & \\
\hline Female & 192 & 30.3 & & 218 & 34.4 & & 22 & 3.4 & \\
\hline Type of school & 355 & 29.4 & $0.298^{a}$ & 418 & 34.7 & $0.367^{a}$ & 44 & 3.7 & $0.008^{a}$ \\
\hline Public & 287 & 30.2 & & 325 & 34.2 & & 40 & 4.2 & \\
\hline Private & 68 & 27.0 & & 93 & 36.9 & & 4 & 1.6 & \\
\hline Age (years) & 355 & 29.5 & $0.247^{a}$ & 418 & 34.7 & $0.632^{\mathrm{a}}$ & 44 & 3.7 & $0.478^{a}$ \\
\hline 8 & 47 & 26.0 & & 62 & 34.2 & & 7 & 3.9 & \\
\hline 9 & 85 & 27.3 & & 114 & 36.6 & & 6 & 1.9 & \\
\hline 10 & 97 & 33.1 & & 93 & 31.7 & & 15 & 5.1 & \\
\hline 11 & 84 & 32.5 & & 97 & 37.6 & & 9 & 3.5 & \\
\hline 12 & 42 & 26.5 & & 52 & 32.5 & & 7 & 4.3 & \\
\hline Household income (quintiles) & 298 & 29.0 & $0.404^{a}$ & 361 & 35.0 & $0.419^{\mathrm{a}}$ & 39 & 3.8 & $0.189^{a}$ \\
\hline 1 (poorest) & 63 & 27.2 & & 78 & 33.6 & & 14 & 6.0 & \\
\hline 2 & 66 & 34.0 & & 58 & 29.7 & & 4 & 2.0 & \\
\hline 3 & 59 & 29.3 & & 70 & 34.8 & & 9 & 4.5 & \\
\hline 4 & 59 & 26.7 & & 90 & 40.7 & & 9 & 4.0 & \\
\hline 5 (richest) & 51 & 28.2 & & 65 & 35.9 & & 3 & 1.7 & \\
\hline Maternal schooling (years) & 347 & 29.7 & $0.756^{\mathrm{a}}$ & 407 & 34.8 & $0.452^{\mathrm{a}}$ & 43 & 3.7 & $0.233^{a}$ \\
\hline$\geq 12$ & 151 & 30.3 & & 182 & 36.5 & & 14 & 2.8 & \\
\hline $9-11$ & 39 & 32.5 & & 37 & 31.0 & & 4 & 3.3 & \\
\hline $5-8$ & 34 & 27.4 & & 37 & 29.8 & & 3 & 2.4 & \\
\hline
\end{tabular}




\begin{tabular}{|c|c|c|c|c|c|c|c|c|c|}
\hline \multirow{2}{*}{ Variables } & \multicolumn{3}{|c|}{$\begin{array}{l}\text { Prevalence of demarcated } \\
\text { opacity }^{d}\end{array}$} & \multicolumn{3}{|c|}{ Prevalence of diffuse opacity ${ }^{d}$} & \multicolumn{3}{|c|}{$\begin{array}{c}\text { Prevalence of enamel } \\
\text { hypoplasia }^{\mathrm{d}}\end{array}$} \\
\hline & $\mathbf{N}$ & $\%$ & $\mathbf{P}$ & $\mathbf{N}$ & $\%$ & $\mathbf{P}$ & $\mathbf{N}$ & $\%$ & $\mathbf{P}$ \\
\hline$\leq 4$ & 123 & 28.9 & & 151 & 35.5 & & 22 & 5.1 & \\
\hline Maternal diabetes & 338 & 29.2 & $0.213^{\mathrm{a}}$ & 405 & 34.8 & $0.363^{a}$ & 42 & 3.6 & $0.986^{a}$ \\
\hline No & 309 & 28.6 & & 381 & 35.4 & & 39 & 3.6 & \\
\hline Yes & 29 & 35.4 & & 24 & 29.3 & & 3 & 3.7 & \\
\hline Maternal infection & 332 & 29.2 & $0.426^{a}$ & 400 & 35.0 & $0.632^{\mathrm{a}}$ & 41 & 3.6 & $0.474^{\mathrm{a}}$ \\
\hline No & 220 & 28.4 & & 276 & 35.7 & & 25 & 3.2 & \\
\hline Yes & 112 & 30.7 & & 124 & 34.0 & & 16 & 4.4 & \\
\hline Maternal malnutrition & 340 & 29.2 & $0.949^{a}$ & 407 & 35.0 & $0.912^{\mathrm{a}}$ & 43 & 3.7 & $0.342^{\mathrm{a}}$ \\
\hline No & 144 & 29.2 & & 236 & 35.1 & & 22 & 3.3 & \\
\hline Yes & 196 & 29.3 & & 171 & 34.8 & & 21 & 4.3 & \\
\hline \multicolumn{10}{|c|}{ Infections in infancy (first three } \\
\hline No & 133 & 30.3 & & 157 & 35.7 & & 15 & 3.4 & \\
\hline Yes & 206 & 28.6 & & 247 & 34.3 & & 29 & 4.0 & \\
\hline \multicolumn{10}{|c|}{ Malnutrition in infancy (first } \\
\hline No & 256 & 28.6 & & 315 & 35.2 & & 31 & 3.5 & \\
\hline Yes & 87 & 31.6 & & 94 & 34.2 & & 11 & 4.0 & \\
\hline \multicolumn{10}{|c|}{ Dental trauma (first three years) } \\
\hline No & 266 & 29.2 & & & & & 35 & 3.8 & \\
\hline Yes & 72 & 28.3 & & & & & 8 & 3.1 & \\
\hline $\begin{array}{c}\text { Brushing with fluorida } \\
\text { paste } \text { (years) }^{\mathrm{b}}\end{array}$ & - & - & - & 405 & 34.8 & $0.674^{a}$ & - & - & - \\
\hline$<3$ & & & & 302 & 35.2 & & & & \\
\hline$\geq 3$ & & & & 103 & 33.7 & & & & \\
\hline \multicolumn{10}{|c|}{ Breastfeeding (exclusively) } \\
\hline & 343 & 29.3 & $0.705^{\mathrm{a}}$ & 409 & 35.0 & $0.804^{a}$ & 44 & 3.8 & $0.920^{\mathrm{a}}$ \\
\hline No & 31 & 28.0 & & 40 & 36.0 & & 4 & 3.6 & \\
\hline Yes & 312 & 29.4 & & 369 & 34.8 & & 40 & 3.7 & \\
\hline \multicolumn{10}{|c|}{ Breastfeeding exclusively } \\
\hline & 355 & 29.5 & $0.189^{a}$ & 418 & 34.7 & $0.276^{\mathrm{a}}$ & 44 & 3.7 & $0.387^{a}$ \\
\hline$\leq 6$ & 204 & 31.0 & & 239 & 36.2 & & 27 & 4.0 & \\
\hline$>6$ & 151 & 27.8 & & 179 & 33.0 & & 17 & 3.1 & \\
\hline Type of delivery & 338 & 29.1 & $0.785^{a}$ & 408 & 35.1 & 0.263 & 43 & 3.7 & $0.086^{a}$ \\
\hline Vaginal & 210 & 29.4 & & 258 & 36.0 & & 32 & 4.5 & \\
\hline Cesarean & 128 & 28.7 & & 150 & 33.6 & & 11 & 2.5 & \\
\hline Prematurity & 340 & 29.1 & $0.645^{\mathrm{a}}$ & 408 & 35.1 & $0.352^{\mathrm{a}}$ & 43 & 3.7 & $0.950^{\mathrm{a}}$ \\
\hline No & 298 & 29.0 & & 355 & 34.5 & & 38 & 3.7 & \\
\hline Yes & 42 & .2 & & 53 & 38.1 & & 5 & & \\
\hline
\end{tabular}

${ }^{a}$ Rao-Scott modified chi-square

${ }^{\mathrm{b}}$ Dental Trauma - only for demarcated opacity and enamel hypoplasia / Brushing with fluoridated toothpaste - only for diffuse opacity ${ }^{\circ}$ Children showed, at least, on teeth with enamel defects (including differents types). 
Table 4 - Adjusted (a) Prevalence Ratios (PR) for prevalence of children with types of enamel defects, according to demographic, socioeconomic and maternal-child characteristics of the sample.

\begin{tabular}{|c|c|c|c|c|c|c|}
\hline & \multicolumn{2}{|c|}{ Demarcated opacities } & \multicolumn{2}{|c|}{ Diffuse opacities } & \multicolumn{2}{|c|}{ Enamel hypoplasia } \\
\hline & $\mathrm{PR}^{\mathrm{a}}(95 \% \mathrm{Cl})$ & $\mathbf{p}$ & $\mathrm{PR}^{\mathrm{a}}(95 \% \mathrm{Cl})$ & $\mathbf{p}$ & $\mathrm{PR}^{\mathrm{a}}(95 \% \mathrm{Cl})$ & p \\
\hline \multicolumn{7}{|l|}{ Variables } \\
\hline Type of school & & & - & - & & 0.149 \\
\hline Public & $1.10(0.88 ; 1.38)$ & 0.363 & & & $2.02(0.76 ; 5.38)$ & \\
\hline Private & 1.0 & & & & 1.0 & \\
\hline Household income (quintiles) & - & - & - & - & & 0.545 \\
\hline 1 & & & & & $2.37(0.64 ; 8.78)$ & \\
\hline 2 & & & & & $0.82(0.14 ; 4.74)$ & \\
\hline 3 & & & & & $1.85(0.48 ; 7.05)$ & \\
\hline 4 & & & & & $1.90(0.51 ; 7.13)$ & \\
\hline 5 & & & & & 1.0 & \\
\hline Age (years) & & 0.470 & - & - & - & - \\
\hline 8 & 1.0 & & & & & \\
\hline 9 & $1.05(0.74 ; 1.48)$ & & & & & \\
\hline 10 & $1.26(0.95 ; 1.70)$ & & & & & \\
\hline 11 & $1.24(0.94 ; 1.63)$ & & & & & \\
\hline 12 & $0.98(0.68 ; 1.44)$ & & & & & \\
\hline Maternal schooling (years) & - & - & - & - & & 0.609 \\
\hline$\geq 12$ & & & & & 1.0 & \\
\hline $9-11$ & & & & & $0.70(0.26 ; 1.95)$ & \\
\hline $5-8$ & & & & & $0.65(0.20 ; 2.11)$ & \\
\hline$\leq 4$ & & & & & $1.17(0.56 ; 2.44)$ & \\
\hline Maternal diabetes & & 0.324 & - & - & - & - \\
\hline No & 1.0 & & & & & \\
\hline Yes & $0.85(0.61 ; 1.19)$ & & & & & \\
\hline Type of delivery & - & - & & 0.274 & & 0.342 \\
\hline Vaginal & & & 1.0 & & 1.0 & \\
\hline Cesarean & & & $0.93(0.82 ; 1.06)$ & & $0.69(0.32 ; 1.52)$ & \\
\hline $\begin{array}{l}\text { Breastfeeding exclusively } \\
\text { (months) }\end{array}$ & & 0.224 & & 0.320 & & \\
\hline$\leq 6$ & 1.0 & & 1.0 & & - & - \\
\hline$>6$ & $0.90(0.75 ; 1.07)$ & & $0.92(0.77 ; 1.09)$ & & & \\
\hline Malnutrition in infancy & & 0.590 & - & - & - & - \\
\hline No & 1.0 & & & & & \\
\hline Yes & $0.95(0.79 ; 1.14)$ & & & & & \\
\hline
\end{tabular}

-Variables that presented $p>0.30$ in bivariate analysis were not included in multivariate analysis model (adjusted by number of permanent teeth). 
Table 5 - Adjusted negative binomial models for extent of enamel defects of the sample, by defect type.

\begin{tabular}{|c|c|c|c|c|c|c|}
\hline \multirow[b]{2}{*}{ Variables } & \multicolumn{2}{|c|}{ Diffuse opacities } & \multicolumn{2}{|c|}{ Demarcated opacities } & \multicolumn{2}{|c|}{ Enamel hypoplasia } \\
\hline & $\operatorname{IRR}^{\mathrm{a}}(95 \% \mathrm{Cl})$ & $\mathbf{p}$ & $\operatorname{IRR}^{\mathrm{a}}(95 \% \mathrm{Cl})$ & $\mathbf{p}$ & $\operatorname{IRR}^{\mathrm{a}}(95 \% \mathrm{CI})$ & $\mathbf{p}$ \\
\hline \multicolumn{7}{|l|}{ Sex } \\
\hline Male & 1.00 & & 1.00 & & 1.00 & 0.132 \\
\hline Female & $1.02(0.84 ; 1.24)$ & 0.827 & $0.96(0.78 ; 1.20)$ & 0.749 & $0.57(0.28 ; 1.18)$ & \\
\hline \multicolumn{7}{|l|}{ Type of School } \\
\hline Public & $0.92(0.72 ; 1.16)$ & 0.472 & $1.18(0.90 ; 1.56)$ & 0.229 & $2.20(0.74 ; 6.54)$ & 0.156 \\
\hline Private & 1.00 & & 1.00 & & 1.00 & \\
\hline \multicolumn{7}{|l|}{ Age (years) } \\
\hline 8 & 1.00 & & 1.00 & & 1.00 & \\
\hline 9 & $0.89(0.66 ; 1.21)$ & & $0.91(0.64 ; 1.29)$ & & $0.32(0.09 ; 1.11)$ & \\
\hline 10 & $0.72(0.52 ; 1.00)$ & & $0.89(0.62 ; 1.26)$ & & $0.80(0.27 ; 2.42)$ & \\
\hline 11 & $0.64(0.47 ; 0.88)$ & & $0.78(0.54 ; 1.13)$ & & $0.45(0.13 ; 1.54)$ & \\
\hline 12 & $0.48(0.33 ; 0.71)$ & $<0.001$ & $0.47(0.31 ; 0.71)$ & $<0.001$ & $0.39(0.11 ; 1.35)$ & 0.324 \\
\hline \multicolumn{7}{|l|}{ Infections in infancy } \\
\hline No & 1.00 & & 1.00 & & 1.00 & \\
\hline Yes & $0.91(0.74 ; 1.12)$ & 0.388 & $0.99(0.79 ; 1.25)$ & 0.979 & $2.15(0.95 ; 4.88)$ & 0.068 \\
\hline \multicolumn{7}{|l|}{$\begin{array}{l}\text { Breastfeeding exclu- } \\
\text { sively (months) }\end{array}$} \\
\hline$\leq 6$ & $0.89(0.72 ; 1.09)$ & 0.257 & $0.85(0.69 ; 1.07)$ & 0.168 & 1.000 .379 & \\
\hline$>6$ & 1.00 & & 1.00 & & $0.70(0.32 ; 1.55)$ & \\
\hline \multicolumn{7}{|l|}{ Prematurity } \\
\hline No & 1.00 & & 1.00 & & 1.00 & \\
\hline Yes & $1.06(0.78 ; 1.45)$ & 0.685 & $1.22(0.87 ; 1.74)$ & 0.200 & $1.76(0.44 ; 7.13)$ & 0.425 \\
\hline \multicolumn{7}{|l|}{ Type of delivery } \\
\hline Vaginal & 1.00 & & 1.00 & & 1.000 .853 & \\
\hline Caesarean & $0.89(0.72 ; 1.11)$ & 0.310 & $0.95(0.75 ; 1.20)$ & 0.675 & $0.92(0.37 ; 2.25)$ & \\
\hline Dental trauma & - & - & & & & \\
\hline No & & & 1.00 & & 1.00 & \\
\hline Yes & & & $1.06(0.80 ; 1.41)$ & 0.676 & $0.82(0.34 ; 1.99)$ & 0.669 \\
\hline $\begin{array}{l}\text { Brushing with } \\
\text { fluoridated toothpaste } \\
\text { (years) }\end{array}$ & & & & & - & - \\
\hline$<3$ & $0.98(0.78 ; 1.24)$ & 0.891 & - & - & & \\
\hline$\geq 3$ & 1.00 & & & & & \\
\hline
\end{tabular}

- Dental trauma - only for demarcated opacity and enamel hypoplasia (extent) / brushing with fluoridated toothpaste only for diffuse opacity (extent)

${ }^{a}$ Count ratio reflects changes in the ratio of extent (the percentage of examined teeth with a particular defect type) in each category compared with reference group 
Figure 1. Diagram showing the number of index teeth $(N=11,122)$ affected by each enamel defect type (or combination).

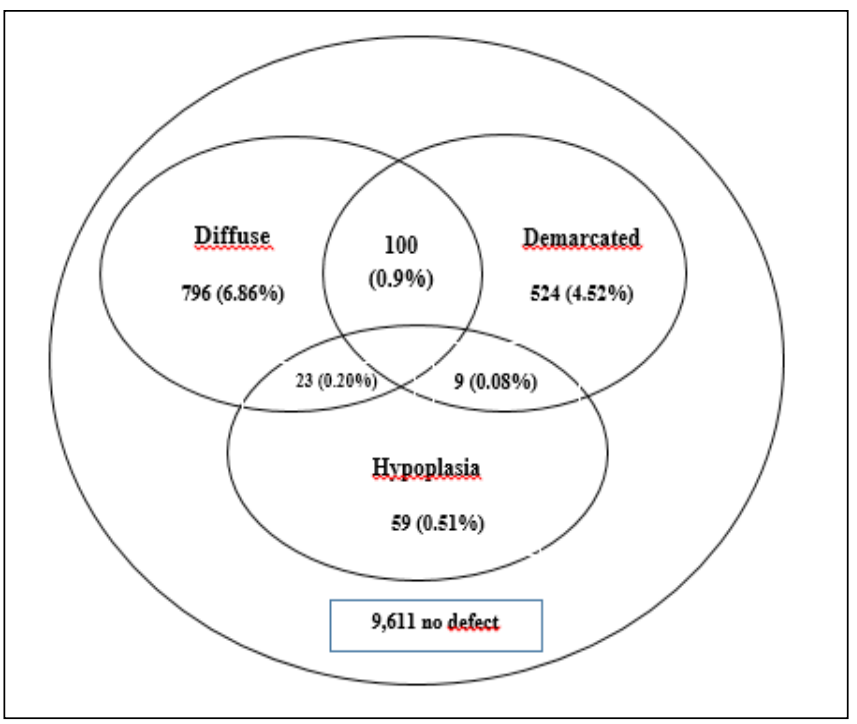

\section{DISCUSSION}

This study found a relatively high prevalence of developmental defects of enamel in Brazilian children, and the extent of those defects was lower among older children than among younger ones. Other child or maternal characteristics were not associated with either the prevalence or extent of enamel defects. Although previous studies have already described the association of biological (periand post-natal) and socioeconomic characteristics with enamel defects $^{5-6,9,13-15}$, there are scarce studies that assessed the occurrence of enamel defects from the perspective of pre-, peri- and post-natal factors in a population-based sample.

The study has a number of limitations which must be addressed. First, about one-third of those selected did not participated, and it is possible that they differed systematically from participants with respect to their enamel defects and their associations. In the absence of data on nonparticipants, it is not possible to determine the direction of any such bias. Second, there is the possibility of recall bias in respect of the early-life exposure data (which may have underestimated our prevalence). This bias may affect the findings, such as underestimated the prevalence. It is important to consider that this was a cross-sectional investigation, than we had inherent limitations in relation to the variables (maternal-child characteristics). We have tried to solve that asking the mothers to send by the children the Child Health Card, which is used for physicians to take information regarding health problem, especially in the first five years of life. However, this attempt was not successful since that a low percentage of mothers sent these cards and also there are some studies questioning the reliability of the data present in this card, especially because the missed data presented in them. Third, it may be that the content of the questionnaire used to obtain those data may have been inappropriate; however, its design and content had input from acknowledged experts in the field of maternal-child health ${ }^{13,19}$. Fourth, the cross-sectional design does not allow effective determination of cause and effect; the best design for this sort of investigation is the prospective cohort study.
Despite its limitations, this study provides new information from a public health perspective and for the scientific community. We used a representative sample of schoolchildren of a Brazilian city with a high response rate. The acceptable level of inter-examiner agreement underpins its internal validity; the large sample size ensured adequate statistical power ( $90 \%)$, and sophisticated statistical analyses were undertaken.

The overall DDE prevalence found in this study (64.0\%) was similar to that reported in Ireland $(56 \%)^{20}$ and in New Zealand $(52.0 \%)^{10}$ for similar age groups. Variations in prevalence estimates may be due to the differences in types of defects studied and the use of different indices and classifications ${ }^{20-21}$. Moreover, the conditions for enamel defects assessment are not standardized: in some studies, teeth were examined with natural light ${ }^{8,22}$; in other studies, they were evaluated with artificial light ${ }^{10,14-15,20}$. These differences may influence the outcome.

Consistent with previous reports, the most common type of DDE was diffuse opacities ${ }^{22-23}$. Corroborating previous findings 9-10,23, the most affected teeth were the maxillary incisors. These data suggest that the Pelotas child population is not atypical in its enamel defect experience.

Diffuse opacities have long been associated with fluoride in drinking water ${ }^{24-26}$. However, their occurrence may be also associated with other factors. A study conducted in Australia showed a higher prevalence of this type of defect (49\%) even with the lack of fluoridation in community water supplies ${ }^{27}$. The authors suggested that children may have consumed other sources of fluoride (toothpaste and/or tablets) ${ }^{27}$, or perhaps the defects were idiopathic. In our study, we examined the influence of brushing teeth with fluoridated toothpaste before age 3 , because before this age, children commonly swallow some of the product during brushing ${ }^{19}$ Diffuse opacities may also result from other types of systemic insults, such as exposure to antibiotics during early childhood, as found in one study after controlling for fluoride intake and the presence of otitis media ${ }^{28}$.

Investigations using prospective cohort studies have shown associations between the occurrence of enamel defects and health problems during the first three years of life ${ }^{15,29}$. Chicken pox and other infections have been linked to enamel hypoplasia ${ }^{29}$. One possible explanation is that an infection (especially of the respiratory tract) producing a febrile illness during the neonatal and postnatal period may affect the ameloblasts ${ }^{30}$.

The current study did not find an association between enamel defects and breastfeeding. A Brazilian study of nutritional risk (breastfeeding) and enamel defects showed that children who were not breastfed had three times the odds of enamel defects over those who had been breastfed ${ }^{6}$. The likely explanation may be the nutritional and immunological properties of milk playing a fundamental role in the nutritional status, growth and development of infants, including the formation of the dental organ ${ }^{13}$. Nevertheless, a study carried out with Finnish 12-year-olds observed that long breastfeeding was associated with a higher risk of mineralization defects (diffuse opacities) in healthy children, possibly because of environmental contaminants that interfere with tooth development ${ }^{11}$. It is interesting to point out that those authors have found that shorter periods of breastfeeding mean longer periods of drinking infant formula, leading to two concerns: (a) the reconstituted formula itself 
has high F, and (b) it may be reconstituted with fluoridated water, thus further increasing the exposure to fluoride.

In this study, no significant association was found between premature birth and the outcome. Prematurity has been described as one of the important causes of enamel defects, mainly in the primary dentition ${ }^{13}$. One likely explanation may be related to the number of schoolchildren having been born prematurely. Moreover, a recent systematic review has shown that there is not evidence that being born prematurely influences development of the permanent teeth ${ }^{31}$. Further studies are needed to assess this association.

It is important to highlight some interesting aspects of our study. Unlike other oral conditions such as dental caries, which has been extensively studied in the context of social and biological, there are scarce studies on enamel defects in permanent teeth from this perspective and this study is in agreement with the holistic approach to health-disease process. Since that it has been demonstrated that enamel defects could be a risk factor for caries occurrence, when planning health policies, health services could indicate a more frequent visiting pattern for those children with DDE, in order to implement preventive measurements for these children.

Knowledge of the epidemiology of enamel defects is important in order to provide basic information within a community or country and between countries. It is also important since it may contribute to the assessment and monitoring of environmental or systemic factors and to detecting possible etiological factors responsible for the occurrence of the enamel defects. Moreover, regardless the design type, we know it is difficult to isolate due to the existence of multiple confounding factors and this manuscript (cross-sectional study) contributes to this discussion. For example, authors have suggested that the increased DDE risk of the teeth is probably related to a critical period of amelogenesis during the ages of 0 -to 3 -years-old, when the child is particularly vulnerable to range of common conditions that can affect enamel development ${ }^{27}$.

\section{CONCLUSION}

In conclusion, enamel defect occurrence in Pelotas children is broadly similar to that observed elsewhere, and while study limitations may in part explain the lack of any association between any of the accepted risk factors and enamel defects, the study results nonetheless raise questions about our current understanding of the etiology of those defects. Having established a relationship between enamel defects and dental caries experience, it is important to identify the etiological risk/associated factors associated with enamel defects. ${ }^{32}$ The publication of null findings such as these is an important means of reducing the risk of publication bias. 


\section{REFERENCES}

1. Jindal C, Palaskar S, Kler S. The prevalence of the developmental defects of enamel in a group of 8-15 years old Indian children with developmental disturbances. J Clinical Diagnostic Res 5: 669-74, 2011.

2. Berbesque JC, Doran GH. Brief communication: physiological stress in the Florida Archaic-enamel hypoplasia and patterns of developmental insult in early North American hunter-gatherers. Am J Phys Anthropol 136: 351-356, 2008 .

3. Federation Dentaire Internationale-Comission on Oral Health, Research and Epidemiology. A review of the developmental defects of dental index (DDE index). Int Dent J 42: 411-26, 1992.

4. Katchburian E, Arana V. Histology and Oral Embryology. Ed. Panamericana, Brazil; 372p, 2004.

5. Chaves AMB, Rosenblatt A, Oliveira OFB. Enamel defects and its relation to life course events in primary dentition of Brazilian children: a longitudinal study. Community Dent Health 24: 31-6, 2007.

6. Massoni AC, Chaves AM, Rosenblatt A, Sampaio FC, Oliveira AF. Prevalence of enamel defects related to pre, peri-and postnatal factors in a Brazilian population. Community Dent Health 26: 143-49, 2009.

7. King NM. Developmental defects of enamel in Chinese girls and boys in Hong Kong. Adv Dent Res 3: 120-25, 1989.

8. Hoffmann RHS, Sousa MLR DE, Cypriano S. Prevalence of enamel defects and the relationship to dental caries in deciduous and permanent dentition in Indaiatuba, São Paulo, Brazil. Cad Saúde Pública 23: 435-44, 2007.

9. Vargas-Ferreira F, Ardenghi TM. Developmental enamel defects and their impact on child oral health-related quality of life. Braz Oral Res 25: 531-7, 2011.

10. Mackay TD, Thomson WM. Enamel defects and dental caries among Southland children. N Z Dent J 101: 35-43, 2005.

11. Alaluusua S, Lukinmaa PL, Koskimies M, Pirinen S, Hölttä P, Kallio M et al. Developmental dental defects associated with long breast feeding. Eur J Oral Sci 104: 493-7, 1996.

12. Agarwal KN, Narula S, Faridi MMA, Kalra N. Deciduous dentition and enamel defects. Ind Pediatr 40: 124-29, 2003.

13. Lunardelli SE, Peres MA. Prevalence and distribution of developmental enamel defects in the primary dentition of pre-school children. Braz Oral Res 19: 144-9, 2005.

14. Arrow P. Risk factors in the occurrence of enamel defects of the first permanent molars among schoolchildren in Western Australia. Community Dent Oral Epidemiol 37: 409-15, 2009.

15. Jälevik B, Norén JG, Klingberg G, Barregard L. Etiologic factors influencing the prevalence of demarcated opacities in permanent first molars in a group of Swedish children. Eur J Oral Sci 109: 230-4, 2001.

16. Goettems ML, Correa MB, Vargas-Ferreira F, Torriani DD, Marques M, Domingues MR et al. Methods and logistics of a multidisciplinary survey of schoolchildren from Pelotas, in the Southern Region of Brazil. Cad Saúde Pública 29: 838-45, 2013.

17. Fisher-Owens SA, Gansky SA, Platt LJ, Weintraub JA, Soobader MJ, Bramlett MD et al. Influences on children's oral health: a conceptual model. Pediatrics 120: 510-20, 2007.
18. Lima FG, Lund RG, Justino LM, Demarco FF, Del Pino FA, Ferreira R. Twenty-four months of external control of fluoride levels in the public water supply in Pelotas, Rio Grande do Sul, Brazil. Cad Saúde Pública 20: 422-9, 2004

19. Rugg-Gunn AJ, Al-Mohammadi SM, Butler TJ. Malnutrition and developmental defects of enamel in 2-to 6-year-old Saudi boys. Caries Res 32: 181-192, 1998.

20. Clarkson JJ, O'Mullane DM. Prevalence of enamel defects/fluorosis in fluoridated and non-fluoridated areas in Ireland. Community Dent Oral Epidemiol 20: 196-9, 1992.

21. Daneshkazemi AR, Davari A. Assessment of DMFT and enamel hypoplasia among junior high school children in Iran. J Contemp Dent Pract 15: 1-7, 2005.

22. Ellwood RP, O'Mullane DM. Association between dental enamel opacities and dental caries in a north Wales population. Caries Res 28: 383-7, 1994.

23. Schluter PJ, Kanagaratnam S, Durward CS, Mahood R. Prevalence of enamel defects and dental caries among 9-year-old Auckland children. $\mathrm{N}$ Z Dental J 104: 145-152, 2008

24. Ekanayake L, Van Der Hoek W. Dental caries and developmental defects of enamel in relation to fluoride levels in drinking water in an arid area of Sri Lanka. Caries Res 36: 398-404, 2002.

25. Suckling GW, Pearce EIF. Developmental defects of enamel in a group of New Zealand children: their prevalence and some associated etiological factors. Community Dent Oral Epidemiol 12: 177-84, 1984.

26. Do LG, Spencer AJ. Decline in the prevalence of dental fluorosis among South Australian children. Community Dent Oral Epidemiol 35: 282-91, 2007.

27. Seow WK, Ford D, Kazoullis S, Newman B, Holcombe T. Comparison of enamel defects in the primary and permanent dentitions of children from a low-fluoride District in Australia. Pediatr Dent 33: 207-12, 2011.

28. Hong L, Levy SM, Warren JJ, Brotfitt B. Association between enamel hypoplasia and dental caries in primary second molars: A cohort study. Caries Res 43: 345-53, 2009.

29. Suckling GW, Herbison GP, Brown RH. Etiological factors influencing the prevalence of developmental defects of dental enamel in nine-year-old New Zealand children participating in a health and development study. J Dent Res 66: 1466-9, 1987.

30. Lygidakis NA, Dimou G, Briseniou E. Molar-incisor-hypomineralisatin (MIH). Retrospective clinical study in Greek children. I. Prevalence and defect characteristics. Eur Arch Paediatr Dent 9: 200-6, 2008.

31. Jacobsen PE, Haubek D, Henriksen TB, Ostergaard JR, Poulsen S. Developmental enamel defects in children born preterm: a systematic review. Eur J Oral Sci $122: 7-14,2014$.

32. Vargas-Ferreira F, Zeng J, Thomson WM, Peres MA, Demarco FF. Association between developmental defects of enamel and dental caries in schoolchildren J Dent. 42: 54-6, 2014. 